\title{
Isolated Scapular Metastasis in a Patient with Gallbladder Carcinoma: Case Report
}

\author{
Mukund Kulkarni ${ }^{1}$, Vijay Ramachandran ${ }^{*}, 2$, Nihar Ranjan Dash ${ }^{1}$, Sujoy Pal ${ }^{1}$, Peush Sahni ${ }^{1}$ and \\ Tushar Kanti Chattopadhyay ${ }^{1}$ \\ ${ }^{I}$ Department of Gastrointestinal Surgery \& Liver Transplantation,All India Institute of Medical Sciences, New Delhi, India \\ ${ }^{2}$ HPB Service, Department of General Surgery, Tan Tock Seng Hospital, 11 Jalan Tan Tock Seng, 308433, Singapore
}

\begin{abstract}
Carcinoma of the gallbladder is considered a disease with grim prognosis owing to frequent locoregional recurrence despite surgery and poor disease specific and overall survival. It can spread directly, transperitoneally as well as via lymphatics, vessels and nerves. Distant spread to almost every organ is described and indicates a very late stage in the course of disease. Hence, evaluation for distant spread is not routinely considered if the disease is confined to locoregional area. We report a case of apparently locally confined Carcinoma gallbladder which manifested with osseous metastasis.
\end{abstract}

Keywords: Carcinoma gallbladder, skeletal metastasis, scapula, adenocarcinoma, Tc 99m labelled scan.

\section{INTRODUCTION}

Gallbladder carcinoma is a very common malignancy among women in North India [1]. The disease most commonly spreads by direct invasion and lymphatic route. The incidence of the latter varies from $35-75 \%$ [2]. Distant metastasis is usually by means of haematogenous spread. Anminski, in his excellent review of the various series in the world literature, reported that metastasis has been reported to virtually every organ in the body which has been corroborated by other authors [3-5]. The spread to various distant organs, although vascular in aetiology, probably occurs in the late stages of the disease via the systemic and retroperitoneal veins and is till recently thought to have little or no surgical significance. We are reporting here a case of otherwise resectable carcinoma gallbladder which presented with painful osseous metastasis.

\section{CASE REPORT}

A 40 year old lady presented with history of dyspeptic symptoms and dull aching, continuous pain in the back for one year. History of significant anorexia and weight loss was forthcoming. Examination revealed a fixed, hard mass $8 \times 7$ cms in size, in the left scapular area (Fig. 1). Breast and thyroid examination was unremarkable. Abdominal examination revealed a hard, palpable gallbladder mass. Abdominal imaging with Ultrasound and MRI revealed a mass in the fundus and body of the gallbladder with cholelithiasis. Radiographs revealed a lytic lesion in the left scapula (Fig. 2). A Tc99m labelled bone scan revealed intense uptake of radiolabelled agent in the left scapular area (Fig. 3). Fine needle aspiration cytology from the scapular lesion revealed adenocarcinoma (Fig. 4). In view of disseminated disease, the patient was offered palliative chemoradiation. However, as neither the patient nor her relatives were

*Address correspondence to this author at the HPB Service, Department of General Surgery, Tan Tock Seng Hospital, 11 Jalan Tan Tock Seng, 308433, Singapore; E-mail: drvijayr@gmail.com consenting for the same, she was discharged at her personal request.

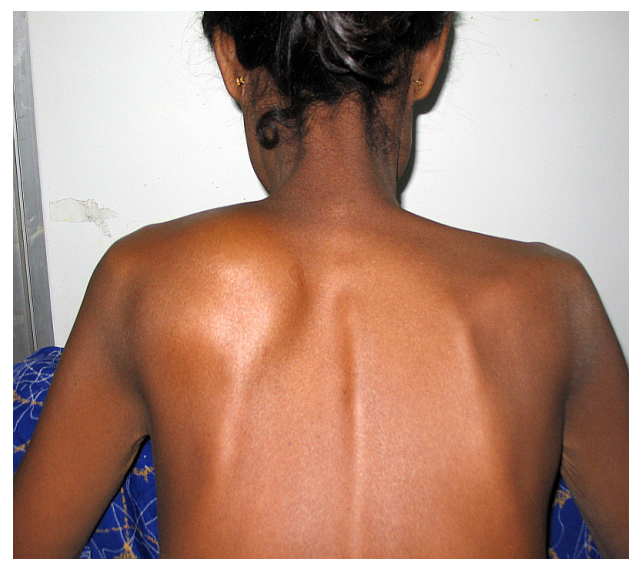

Fig.(1). Mass in the left scapular area

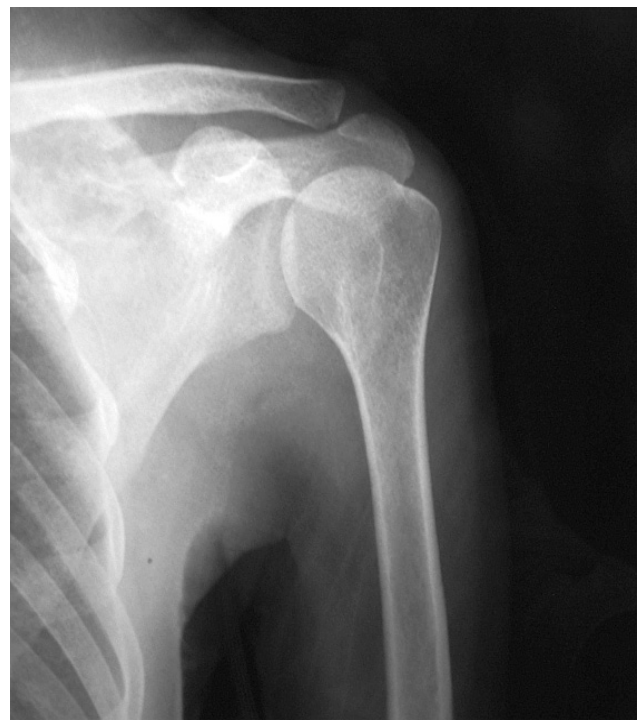

Fig. (2). Radiograph showing a lytic lesion in the left scapula. 


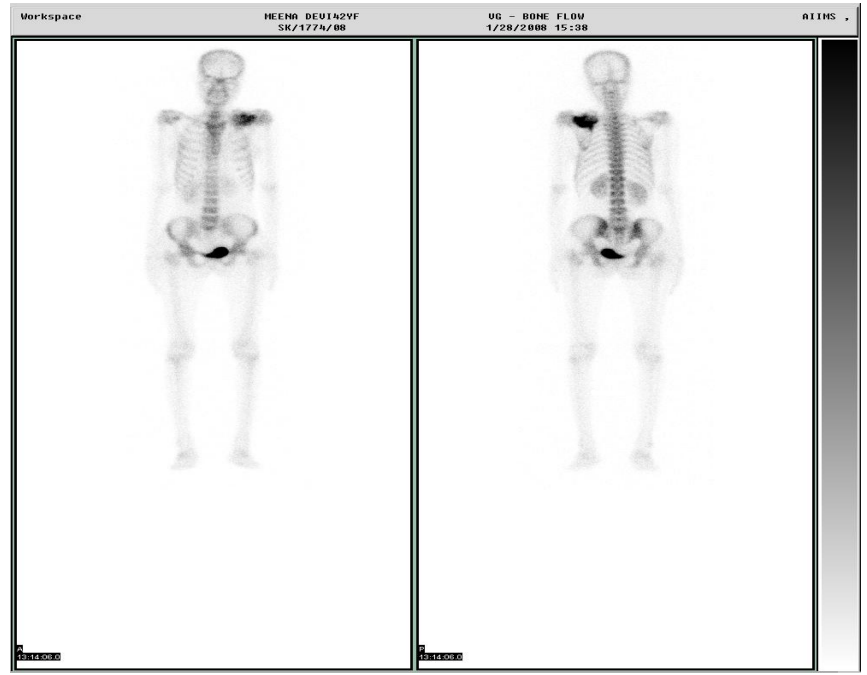

Fig. (3). Tc99m labelled bone scan showing intense uptake of radiocolloid in the left scapular area.

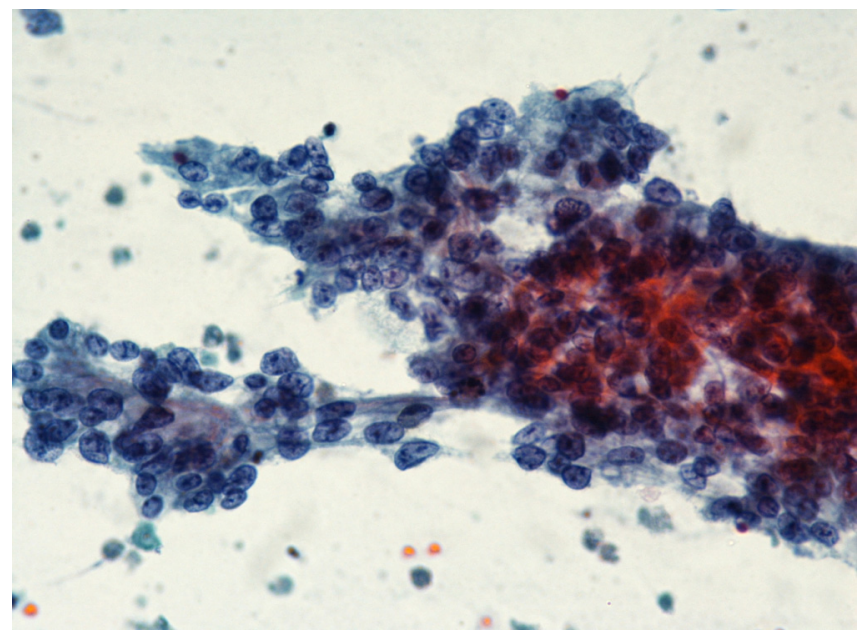

Fig. (4). Fine needle aspiration cytology smear from scapular mass showing fragments from an adenocarcinoma, comprising of crowded cluster of tumour cells with vesicular nuclei, irregular nuclear margins and prominent nucleoli. (May Grunwald Giemsa X 400).

\section{DISCUSSION}

It is unusual for patients with otherwise resectable carcinoma gallbladder to present with painful osseous metastasis. Though radiograph and bone scan was suggestive of the nature of the lesion, the diagnosis of metastasis was confirmed by aspiration cytology from the mass. A review of literature revealed that cases of extra abdominal spread of gallbladder cancer to the skull, vertebral column, iliac crest, femur, orbit [1, 6, 7], skin [8], CNS [9] and heart [10] have been reported in cases of unresectable carcinoma gallbladder. However, metastasis to the scapula, in a case of resectable carcinoma gallbladder, has been reported for the first time.

\section{CONCLUSION}

Carcinoma gall bladder is often associated with a dismal prognosis owing to increased propensity for metastasis by multiple routes. Early hematogenous spread can occur via retroperitoneal veins and render it incurable.

\section{ACKNOWLEDGMENT}

We acknowledge the support of the Departments of Nuclear Medicine, Radiology \& Pathology, AIIMS, New Delhi.

\section{REFERENCES}

[1] Misra A, Misra S, Chaturvedi A, Srivastava PK. Orbital metastasis from gall bladder carcinoma. Br J Radiol 2002; 75: 72-3.

[2] Fahim RB, McDonald JR, Richards JC, Ferris DO. Carcinoma of the gallbladder: a study of its modes of spread. Ann Surg 1962; 156: 114-24.

[3] Arminski TC. Primary carcinoma of the gallbladder: a collective review with the addition of twenty-five cases from the grace hospital, Detroit, Michigan. Cancer 1949; 379: 2.

[4] Kirshbaum JD, Kozoll DD. Carcinoma of the gallbladder and extrahepatic bile ducts: a clinical and pathological study of 117 cases in 13,330 Necropsies. Surg Gynecol Obst 1941; 740: 73.

[5] Tragerman LJ. Primary carcinoma of the gallbladder: review of 173 cases. Calif Med 1953; 78: 431.

[6] Singh S, Bhojwani R, Singh S, Bhatnagar A, Saran RK, Agarwal AK. Skeletal metastasis in gallbladder cancer. HPB (Oxford) 2007; 9(1): 71-2.

[7] Kumar A, Bhargava SK, Upreti L, Kumar J. Disseminated osteoblastic skeletal metastasis from carcinoma gall bladder - a case report. Ind J Radiol Imaging 2003; 13: 37-9.

[8] Bardaji M, Roset F, Puig A, Badal J, Fernandez-Layos MJ. Cutaneous metastatic adenocarcinoma of gallbladder origin: report of a case and review of the literature. Hepatogastroenterology 1998; 45: 930-31.

[9] Kawamata T, Kawamura H, Kubo O, Sasahara A, Yamazato M, Hori T. Central nervous system metastasis from gallbladder carcinoma mimicking a meningioma. Case illustration. J Neurosurg 1999; 6: 1059

[10] Suganuma M, Marugami Y, Sakurai Y, et al. Cardiac metastasis from squamous cell carcinoma of gallbladder. J Gastroenterol $1997 ; 6: 852-56$. 